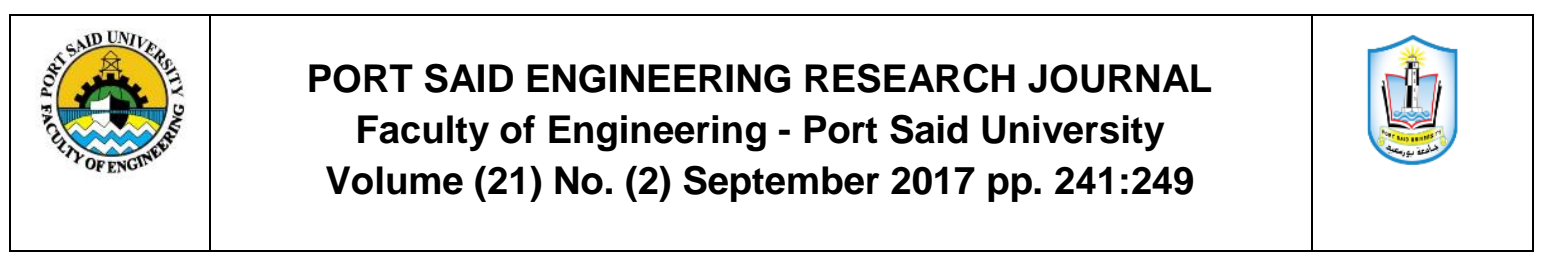

\title{
Experimental Study for the Effect of Static and Dynamic Loads on Clay Utilizing Geofoam
}

\author{
M. El Gendy ${ }^{1}$, I. El Araby' ${ }^{2}$ W. El Kamash ${ }^{3}$,E. Sallam ${ }^{4}$ and A. El Labban ${ }^{5}$.
}

\begin{abstract}
The recent and continuous industrial development at Port-Said necessitates many factories and gas plants to be constructed on its thick graduated clay soil. Accordingly, suitable foundation systems are to be developed to resist the expected dynamic effects and vibrations of the heavy machinery and rotating masses utilized for such activities. Expanded Polystyrene (EPS) Geofoam was introduced as an efficient dynamic damper and lightweight solution for many geotechnical problems. In this research, the effect of the static loads in machinery shutdown state and the dynamic loads in working state on the settlement behavior of a square footing resting on Port-Said clay is studied experimentally, both in the presence and absence of EPS. The results showed that the use of EPS can considerably reduce the maximum settlement under machine foundation.
\end{abstract}

key words: Machine foundation, EPS, Expanded Polystyrene Geofoam, Dynamic analysis.

\section{INTRODUCTION}

Machine foundations require special consideration due to the combination of dynamic and static loads. The suitable foundation is selected, depending on the machine type. Foundations that support the machines are subjected to vibrations caused by machine unbalanced forces. The amplitude of vibration and the natural frequency of a machine foundation soil system are the most important parameters in designing a machine foundation.

Prakash and Puri [1] classified types of machines that generate different periodic forces depending on the operating speed of such machine to three categories: a) Reciprocating machines, b) Impact machines, and c) Rotary machines. The magnitude and characteristics of the operating loads depend on the type, size, speed, and machine layout. Fattah, et al, [2] investigated the effect of the foundation geometry, the amplitude and frequency of the dynamic load, and the damping ratio on the structural behaviour of a machine foundation on piles in homogeneous sandy soil. Hassan, et al,

${ }^{I}$ Professor of Geotechnical Engineering and Foundations, Faculty of Engineering, Port Said University, Egypt.

${ }^{2}$ Associate Professor, Faculty of Engineering, Port Said University, Egypt. ${ }^{3}$ Associate Professor, Faculty of Engineering, Suez Canal University, Egypt. ${ }^{4}$ Assistant Professor, Faculty of Engineering, Port Said University, Egypt. ${ }^{5}$ PhD candidate, Faculty of Engineering, Port Said University, Egypt.
[3] studied the dynamic behaviour of piled foundation by computer software. Many parameters such as soil type, soil damping, pile length, pile type, foundation mass and embedment depth were investigated. They presented an important guide for the researchers to reduce the trials of the design process. Vlad [4] presented some practical cases of machine foundation vibrations; which were technically evaluated throughout a program of vibration measurements. Then, he illustrated some corrective solutions leading to eliminate those dangerous vibrations. EPS foam was one of those vibration absorbers.

Alzawi [5] presented comprehensive experimental and numerical investigations on the use of in-filled geofoam trench barriers to scatter machine foundations vibration, taking into account all the parameters that adequately describe the vibration screening process. Experimental results confirmed that in-filled geofoam trench barriers can effectively reduce the transmitted vibrations. They also developed an artificial neural network (ANN)model; which is capable to predict the in-filled geofoam wave barrier protective effectiveness in different soil profiles with different geometric dimensions. Elragi [6] presented a comprehensive review on EPS geofoam and discussed many practical examples of its engineering application. Abdelrahman and Elragi [7] showed, both experimentally and numerically, that the natural weak clay soil underneath the footing might be 
replaced efficiently by EPS blocks in order to reduce the footing settlement under static loading.

The aim of the present investigation is to study the settlement behavior of a square footing specimen resting on Port-Said clay (in the presence of EPS geofoam as a settlement reducer), when subjected to both monotonic and dynamic loading.

\section{EXPERIMENTAL MODELING}

The experimental studies in this research were performed in the geotechnical laboratory of the faculty of the engineering at Port-said University.

\subsection{Investigated Soil}

Soft clay is used for the current experimental investigation. The clay is obtained from pile excavation-photo (1)- at depth $40 \mathrm{~m}$ from the new ZOHR gas treatment plant located at the west of Port-said city, as shown in Figure (1).

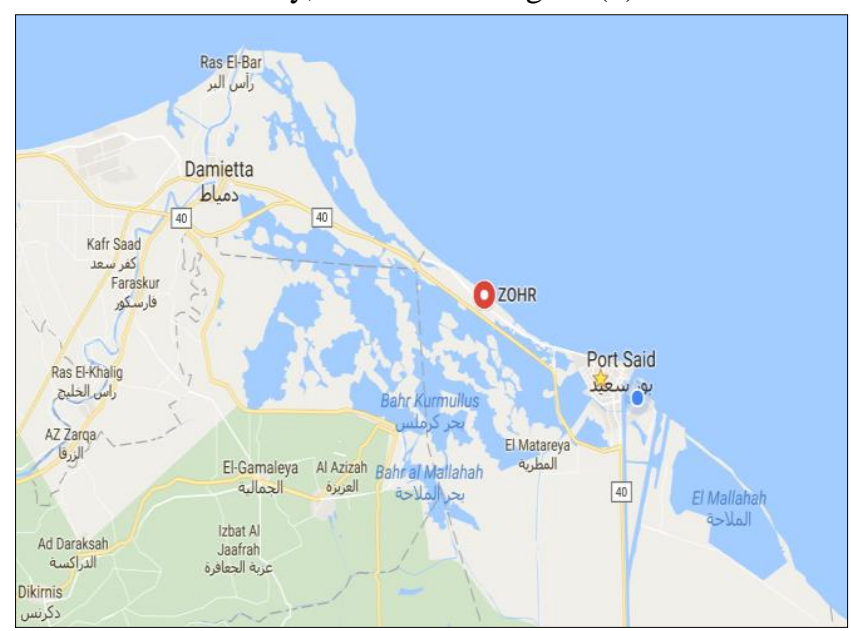

Fig. 1 Location of soil sample extraction at ZOHR plant.

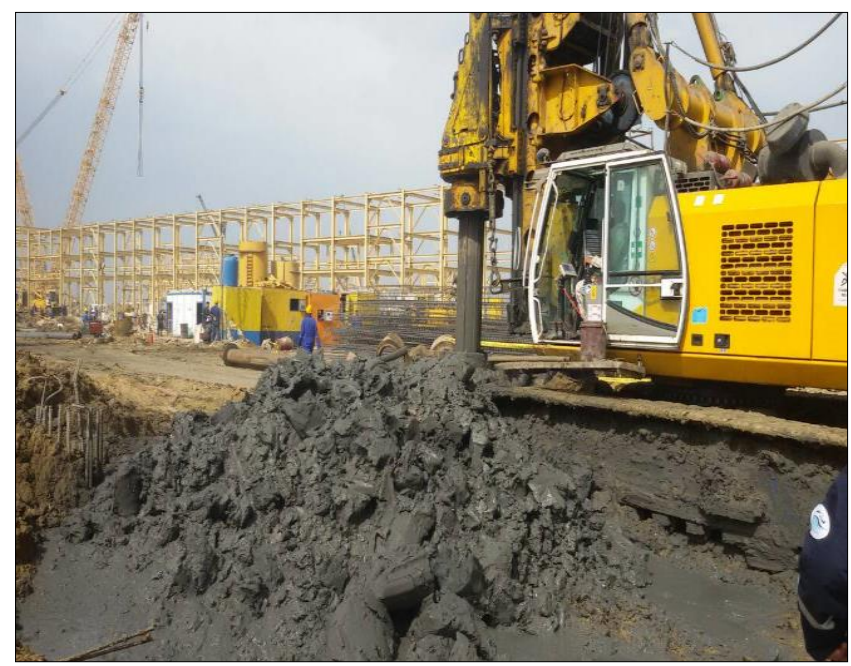

Photo 1 Soil sample extraction
Several laboratory tests were executed to determine the properties of the tested soil.

The average properties of clay used in tests are as follows:

Water content $\left(\mathrm{W}_{\mathrm{c}}\right)=68 \%$

Bulk Unit Weight $\left(\gamma_{\mathrm{b}}\right)=16.0 \mathrm{kN} / \mathrm{m}^{3}$

Shrinkage $\operatorname{Limit}($ S.L $)=13.5 \%$

Liquid Limit (L.L) $=45.0 \%$

Plastic Limit (P.L) $=21.0 \%$

Plasticity Index (P.I) $=24.0 \%$

Two specimens were tested under Oedmeter apparatus to measure a soil's consolidation properties. Oedometer tests were performed by applying different loads to a soil sample and measuring the deformation response. The maximum applied stress was $850 \mathrm{kN} / \mathrm{m}^{2}$ for all tests. Figure (2) shows the void ratio values with the different stresses which were applied gradually on Oedemeter test.

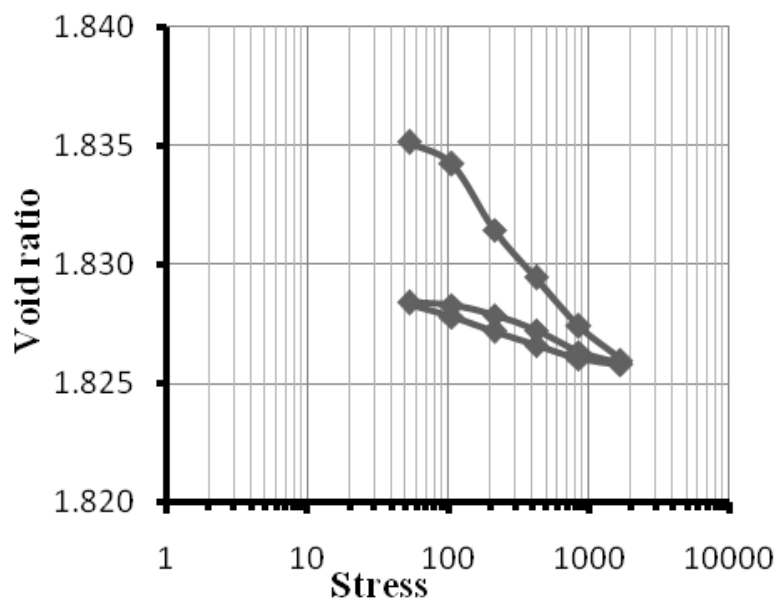

Fig. 2 Variation of void ratio with log stress

The compressibility of the clay layers was evaluated in laboratory to calculate the consolidation properties which are as follows:

Average voids ratio $\left(\mathrm{e}_{\mathrm{o}}\right)=1.83$

Coefficient of volume compressibility $=2 \mathrm{~cm}^{2} / \mathrm{kN}$

Coefficient of consolidation $\left(\mathrm{C}_{\mathrm{v}}\right)=0.179 \mathrm{~m}^{2} /$ year

Coefficient of permeability $\left(\mathrm{k}_{\mathrm{z}}\right)=1 \mathrm{E}-9 \mathrm{~cm} / \mathrm{sec}$

Drained Modulus of Elasticity $\left(\mathrm{E}_{\mathrm{d}}\right)=2130 \mathrm{kN} / \mathrm{m}^{2}$

Over-consolidation Ratio $(\mathrm{OCR})=1.8$

Compression Index $\left(\mathrm{C}_{\mathrm{c}}\right)=0.413$

Recompression Index $\left(\mathrm{C}_{\mathrm{r}}\right)=0.11$

\subsection{Used Geofoam}

In the current study, EPS is serving as settlement reducer and vibration damper with the same area of footing $15 \times 15 \mathrm{~cm}$, thickness $5 \mathrm{~cm}$ and density $0.3 \mathrm{kN} / \mathrm{m}^{3}$. 


\subsection{BoundaryTank}

Photo (2) shows the reinforcement concrete tank having dimensions of $1.40 \times 1.40 \mathrm{~m}$ with $1 \mathrm{~m}$ in depth with soil filled till $0.8 \mathrm{~m}$ of its height. The wall thickness of the tank is $7 \mathrm{~cm}$ to be rigid enough to prevent any lateral side movement during testing under dynamic loads. The inside walls of the tank were covered by linoleum to prevent the absorption of water from the soil and maintain the moisture content as much as possible. The dimensions were sufficient to minimize any effect of dynamic load reflection from tank walls or bottom.

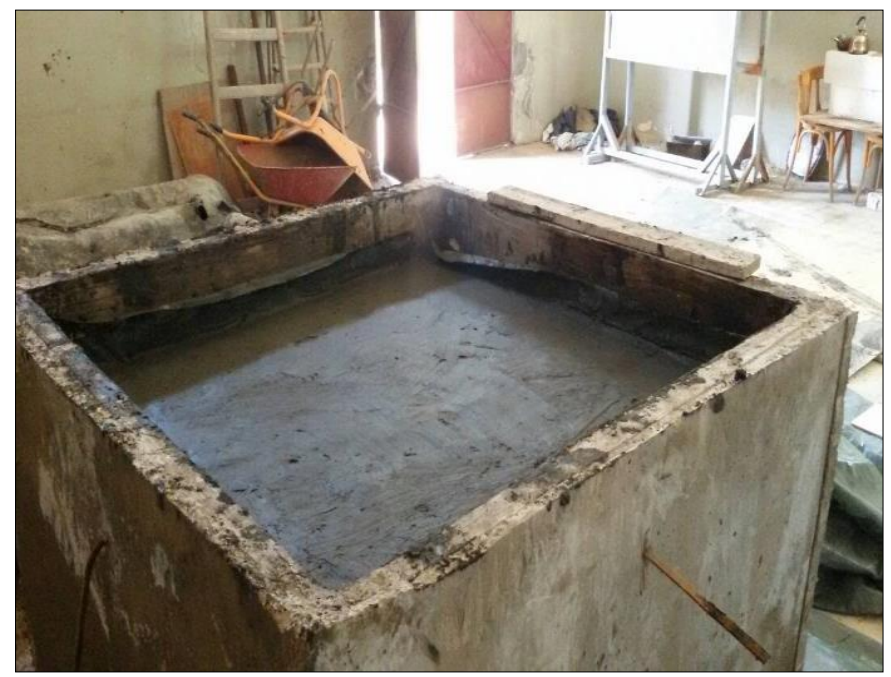

Photo 2 Boundary tank

\subsection{Foundation and Loading}

The footing models were made of $15 \times 15 \times 3 \mathrm{~cm}$ thick steel plates. As shown in Photo (3), the loading frame consists of two parts:

- The first part: is fixed to the four side walls of the square tank and it consists of $7 \times 7 \times 0.2 \mathrm{~cm}$ welded box sections.

- The second part: is movable arm of $90 \mathrm{~cm}$ length and $6 \times 6 \times 0.2 \mathrm{~cm}$ box cross-section, mounted at the centerline of the tank.

Two steel plates, one above the other, were welded to the movable vertical arm in order to transmit the applied loads tothe center of footing. The first is a $50 \times 30 \mathrm{~cm}$ and $0.8 \mathrm{~cm}$ thick rectangular plate fixed directly under the motor to generate the dynamic loading, while the second is a $20 \times 20 \mathrm{~cm}$ and $0.8 \mathrm{~cm}$ thick square plate; which is fixed on 4-legs apart from the motor to apply the static loading. A steel box of 50 $\mathrm{cm}$ height is put above the top plate to apply the static loading during simultaneously with the vibrating dynamic load.

The soft clay was consolidated by applying a uniform vertical pressure on the steel plate to bring the soil bearing capacities to 20,40 and $60 \mathrm{kN} / \mathrm{m}^{2}$.
During the vertical consolidation, the settlement of the steel plate was measured by two dial gauges fixed on the top surface of the footing specimen. The dial gauge had a maximum travel of $25 \mathrm{~mm}$ and an accuracy of $0.01 \mathrm{~mm}$ and it would be reset after each $25 \mathrm{~mm}$.

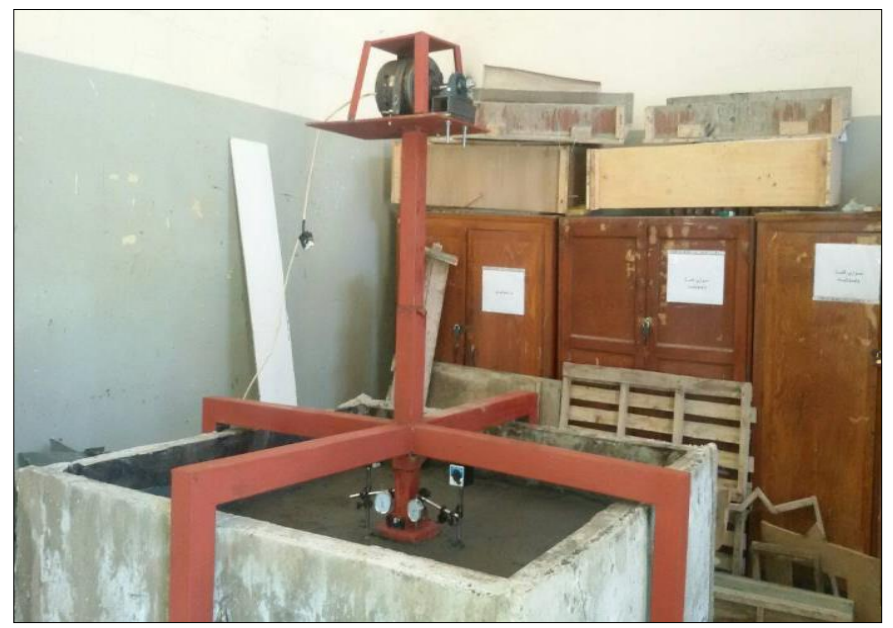

Photo 3 Experimental model setup

\subsubsection{Static Loading}

The weight of the movable part which acts as the static load during all the tests is $0.34 \mathrm{kN}$. A load of $0.11,0.56$ and $1.01 \mathrm{kN}$ were chosen to act on the first plate to give a prestress clay of bearing capacity equal to 20,40 and $60 \mathrm{kN} / \mathrm{m}^{2}$, respectively.

\subsubsection{Dynamic Loading}

Two motors with different velocities; 1000 and $450 \mathrm{rpm}$ were used to generate the dynamic loading. From elementary dynamics and referring to Florjanic and Frei [8] a mass $m_{e}$ connected to a motor shaft with an arm of $y$ rotating at a circular frequency of $\omega$ produces a force at any instant in time of $F_{m}$

$F_{m}=\mathrm{U} \cdot \omega^{2}(1)$

where:

$\mathrm{U}$ is the unbalance force $=m_{e} . y$

$\omega$ is the circular operating frequency of the

motor, $(\omega=2 \pi \mathrm{f})$

$f$ is the operating frequency.

In this study, the rotating mass was changed with the different motors velocity to get the same dynamic force. Thus, the only variable is the circular operating frequency of the motor. The rotating mass is equal to 0.65 and $3.2 \mathrm{Nfor}$ the motor frequency 1000 and $450 \mathrm{rpm}$; respectively, effect on the same distance in the two cases which equal $7 \mathrm{~cm}$ from the center of motor shaft. According to equation(1), the generated dynamic forces are $0.05 \mathrm{kN}$

\section{STUDIED PARAMETERS}


In this study, Eighteen case studies have been tested in the laboratory to investigate the settlement response of footing resting on Port-said medium soft clay. The main features of the study for experimental model are shown in Figure (3) and divided to main six groups:

\section{Group (1):}

Footing subjected to static load without utilizing EPS

Group (2):

Footing subjected to static load with utilizing EPS

Group (3):

Footing subjected to dynamic load with frequency 1000 rpm without utilizing EPS.

\section{Group (4):}

Footing subjected to dynamic load with frequency 1000 rpm with utilizing EPS.

\section{Group (5):}

Footing subjected to dynamic load with frequency 450 rpm without utilizing EPS.

\section{Group (6):}

Footing subjected to dynamic load with frequency 450 rpm with utilizing EPS.

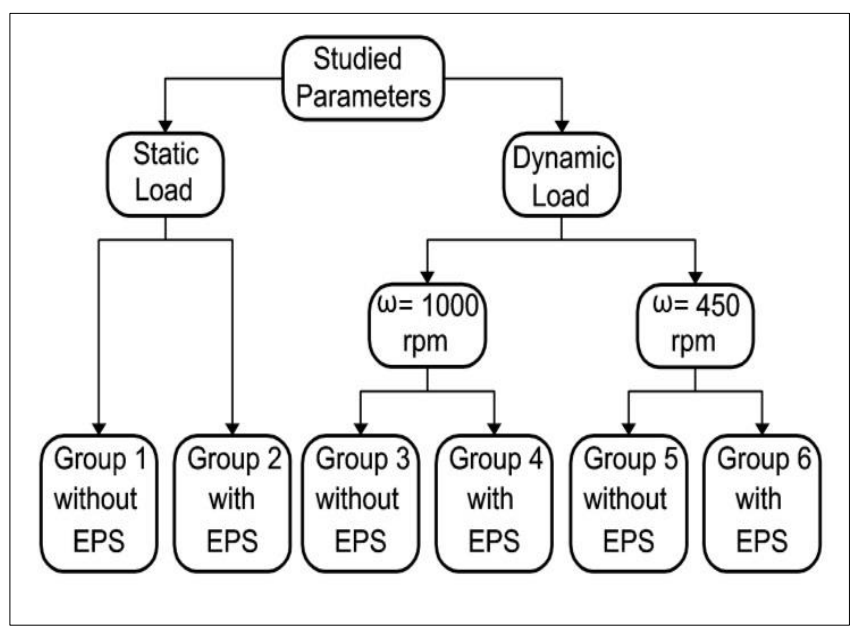

Fig. 3 Classification of parametric study

Each group has three case studies according to the subjected stress 20,40 and $60 \mathrm{kN} / \mathrm{m}^{2}$, forming eighteen cases.

In case of static loads, load of $0.11,0.56$ and $1.01 \mathrm{kN}$ was chosen to give a pre-stress clay of bearing capacity equal to 20, 40 and 60kN/Mm, respectively. Under dynamic loads, and after minus the value of dynamic force, load of $0.06,0.51$ and $0.96 \mathrm{kN}$ was chosen to get the above stresses.

\section{TESTING PROCEDURE}

The following work sequence is applied to configure the testing model.
- The clay used in this study is saturated medium soft clay obtained from the result of excavation which executing for casting the piles at Zohr project; the new gas plant at west of Port-said city.

- The clay is stored at the soil laboratory in wooden box covered from all the sides by linoleum and also during the test to keep their water content unchanged.

- The tank is filled by the clay in layers until reach the total required height $(80 \mathrm{~cm})$. After each group, the half of clay layers is changed and rechecked water content $\left(\mathrm{W}_{\mathrm{c}}\right)$ to ensure that changes in $\mathrm{W}_{\mathrm{c}}$ didn't exceed $\pm 5 \%$

- After reaching the top of clay level $(80 \mathrm{~cm})$, the final soil surface is carefully leveled

- The footing is carefully placed on the tank centerline, two dial gauge are fixed on the top of footing, Then the vertical load is applied.

- In case of using EPS ; (Group 2,4 and 6), EPS is placed at the same level of clay under the footing with the same dimension $15 * 15 \mathrm{~cm}$.

-The loading is applied by increments for each group resulting contact stresses ranging from 20 to $60 \mathrm{kN} / \mathrm{m}^{2}$. Each load step on the footing is keep up for around two days in all the case studies.

Photo (4) and (5) shows the experimental model during and after subjected to loading.

\section{TEST RESULTS}

5.1. Behavior of Clay under Static Load (Groups 1,2) Static loads included two models, denoted as group 1 without using EPS and group 2 with utilizing EPS. As described in Table (1), the partial settlement was measured under applied stresses 0.2 and $40 \mathrm{kN} / \mathrm{m}^{2}$ after 2 days for each, while that final settlement was measured after six days (8640 minutes) under applied stress $60 \mathrm{kN} / \mathrm{m}^{2}$.The measured settlements for the three studied cases for group 1 ranged between 4 and $29 \mathrm{~mm}$, while for the same stresses but with utilizing EPS (group 2) ranged between 0.6 and $8.6 \mathrm{~mm}$. It is clear that the existence of EPS has a noticeable effect in reducing the measured settlements for different applied pressures.

In this case, reductions in the total settlements was about $70 \%$ and giving the highest reduction in the total settlements of all the studied groups.

Figure (4) presents time-settlement curve for the cases of static loads for six days loading period. 


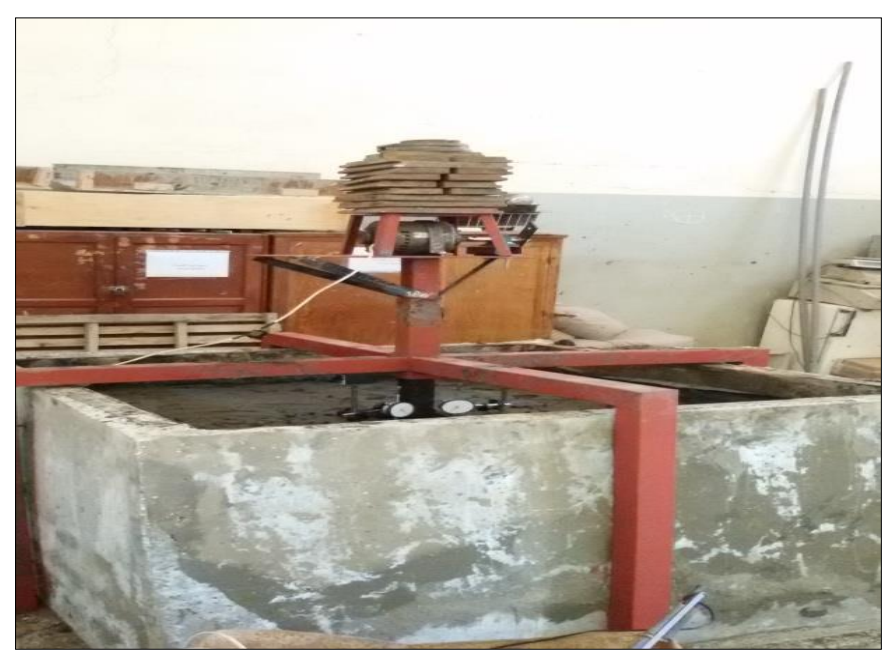

Photo 4 Experimental model during loading

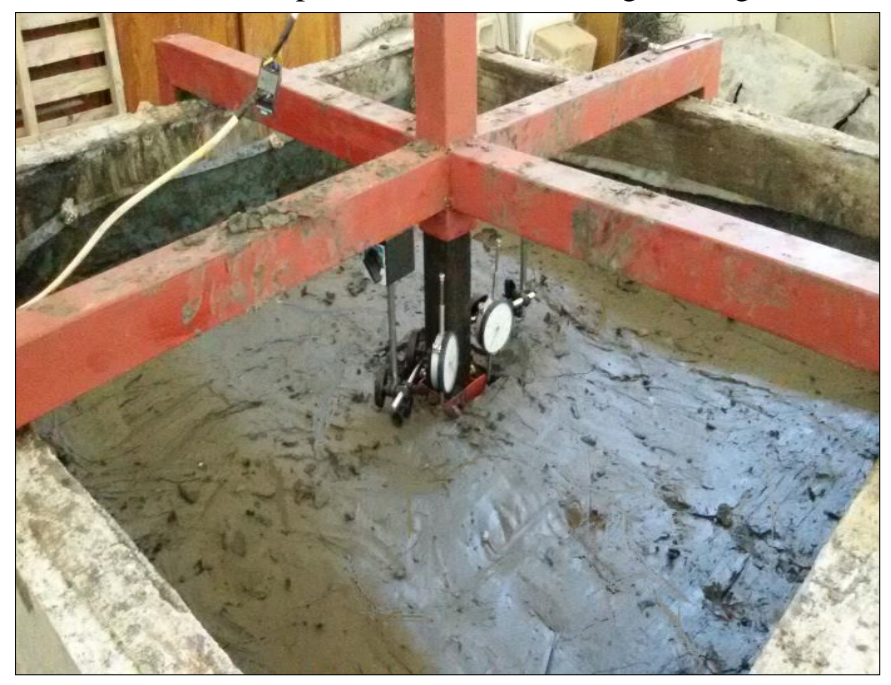

Photo 5 Soil settlement after loading

Table 1:Maximumsettlement results for static load cases

\begin{tabular}{|c|c|c|c|}
\hline \multirow{2}{*}{$\begin{array}{c}\text { Applied } \\
\text { Stress } \\
\left(\mathrm{kN} / \mathrm{m}^{2}\right)\end{array}$} & \multicolumn{2}{|c|}{ Max. Settlement (mm) } & \multirow{2}{*}{$\begin{array}{c}\text { Decrease } \\
\text { Percentage }\end{array}$} \\
\cline { 2 - 3 } 20 & 4.6 & 1.9 & $58.7 \%$ \\
\hline 40 & 8.6 & 5.3 & $38.4 \%$ \\
\hline 60 & 16.6 & 11.3 & $31.9 \%$ \\
\hline
\end{tabular}

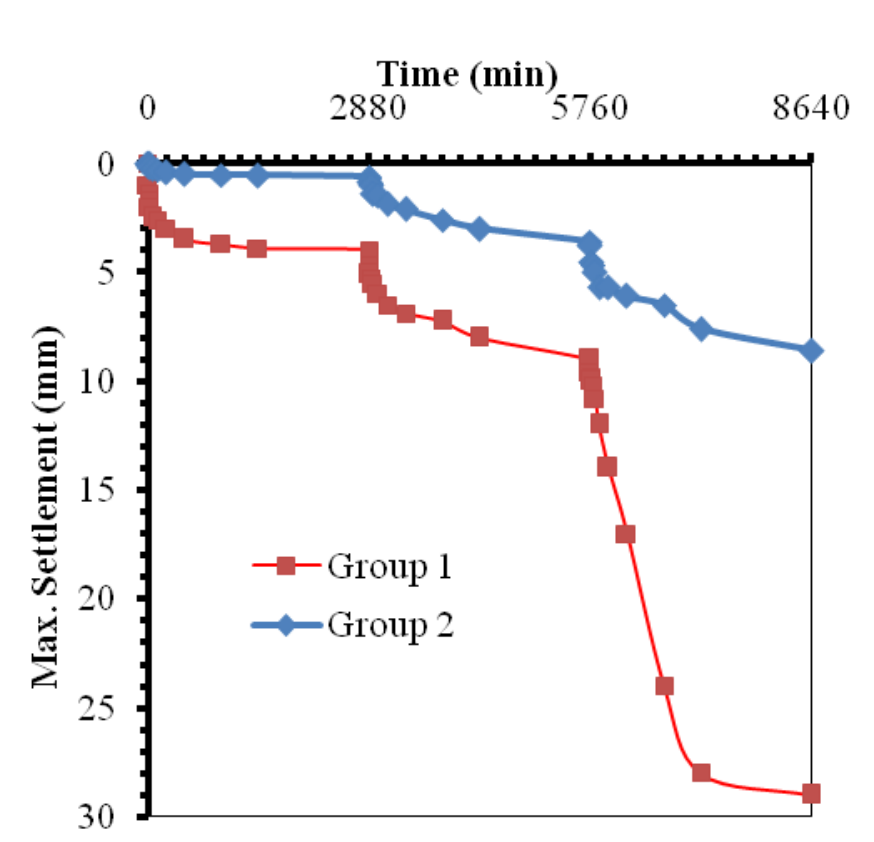

Fig. 4 Time-settlement curve for the cases of static loads

\subsection{Behavior of Clay under Dynamic Load with $\omega=1000 \mathrm{rpm}$ (Groups 3,4)}

Dynamic loads with angular frequency $(\omega)=1000 \mathrm{rpm}$ included two models, denoted as group 3 without using EPS and group 4 with utilizing EPS. The recorded maximum settlements for group 3 are shown in Table (2) ranged between 4.6 and $16.6 \mathrm{~mm}$, giving reductions in the settlements values ranging between $58.7 \%$ and $31.9 \%$ in case of using EPS. Figure (5) also shows a settlement rate with time for groups 3,4

Table 2: Maximum settlement results for cases of dynamic loads with $\omega=1000 \mathrm{rpm}$

\begin{tabular}{|c|c|c|c|}
\hline \multirow{2}{*}{$\begin{array}{c}\text { Applied } \\
\text { Stress } \\
\left(\mathrm{kN} / \mathrm{m}^{2}\right)\end{array}$} & \multicolumn{2}{|c|}{ Max. Settlement (mm) } & \multirow{2}{*}{$\begin{array}{c}\text { Decrease } \\
\text { Percentage }\end{array}$} \\
\cline { 2 - 3 } 20 & 4 & 0.6 & $85.0 \%$ \\
\hline 40 & 9 & 3.6 & $60.0 \%$ \\
\hline 60 & 29 & 8.6 & $70.3 \%$ \\
\hline
\end{tabular}




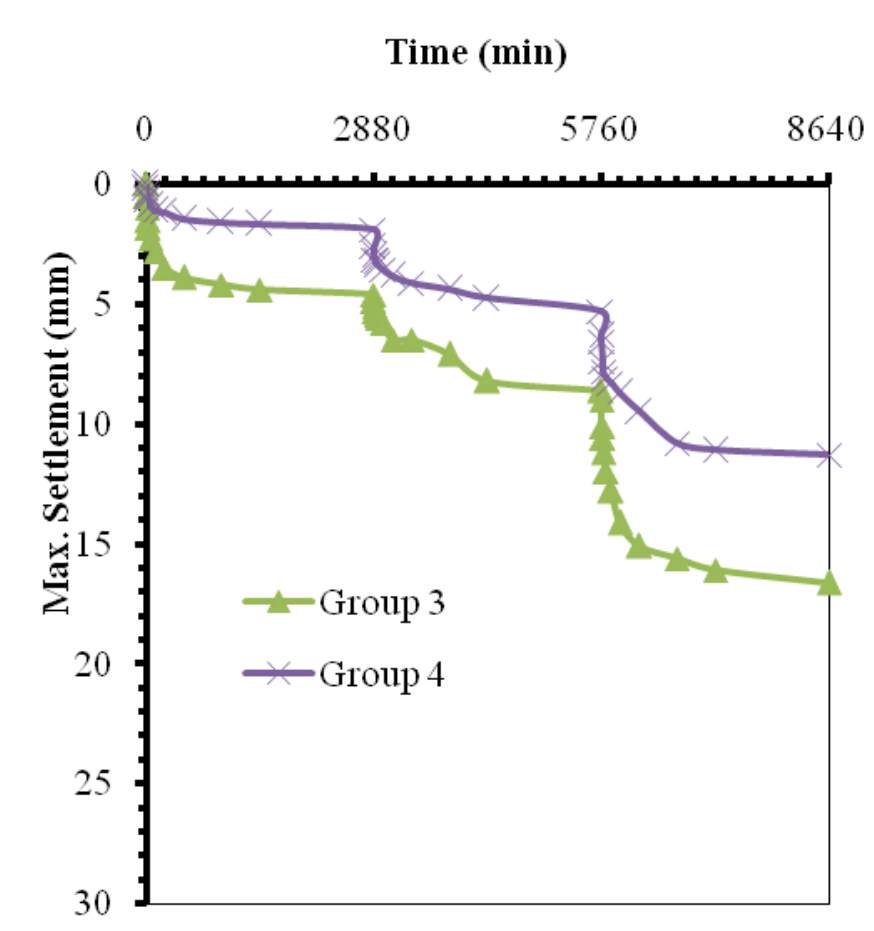

Fig. 5 Time-settlement curve for the cases of dynamic loads with $\omega=1000 \mathrm{rpm}$

5.3. Behavior of Clay under Dynamic Load with $\omega=450$ rpm(Groups 5,6)

Dynamic loads with $\omega=450 \mathrm{rpm}$ included two models, denoted as group 5 without using EPS and group 6 with utilizing EPS. The Time-settlement curve for groups 5 and 6 is shown in Figure (6). The figure shows a relatively decreasing in settlement value when using EPS under all the applied stress stages except for the last loading step. The recorded maximum settlements for groups 5 and 6 are shown in Table (3) ranged between 6 and $14.5 \mathrm{~mm}$, giving low reductions in the settlements values $16.7 \%$ and $4 \%$ in case of using EPS at stresses values 20 and $40 \mathrm{kN} / \mathrm{m}^{2}$, respectively, giving the lowest reduction in the total settlements of all the studied groups.

At applied stresses $60 \mathrm{kN} / \mathrm{m}^{2}$, EPS didn't decrease the settlement value, but increase by $21.4 \%$.In this case, A large amplitude oscillations was produced due to the resonant frequencies. This phenomenon occurred when the frequency of the motor matches the system's natural frequency.

Figure (7),(8) and (9) shows a settlement rate with the time at applied stresses 20, 40 and $60 \mathrm{kN} / \mathrm{m}^{2}$ after 2, 4 and 6 days, respectively. Furthermore, Figure (10) shows accumulation Time -Settlement curve of all groups under all different applied stresses
Table 3: Maximum settlement results for cases of dynamic loads with $\omega=450 \mathrm{rpm}$

\begin{tabular}{|c|c|c|c|}
\hline \multirow{2}{*}{$\begin{array}{c}\text { Applied } \\
\text { Stress } \\
\left(\mathrm{kN} / \mathrm{m}^{2}\right)\end{array}$} & \multicolumn{2}{|c|}{ Max. Settlement (mm) } & \multirow{2}{*}{$\begin{array}{c}\text { Decrease } \\
\text { Percentage }\end{array}$} \\
\cline { 2 - 3 } & Group 5 & Group 6 & $16.7 \%$ \\
\hline 20 & 6 & 5 & $4.0 \%$ \\
\hline 60 & 10 & 9.6 & $-21.4 \%$ \\
\hline
\end{tabular}

Figure (11),(12) and (13) shows the variation of the measured settlement at the end of each loading step with the applied pressure for all the case studies. Test results showed a steep increase in settlements with increasing the applied pressure. It is clear that the decreasing rate of settlements in the applied pressure over $40 \mathrm{kN} / \mathrm{M}^{2}$ at the most groups.

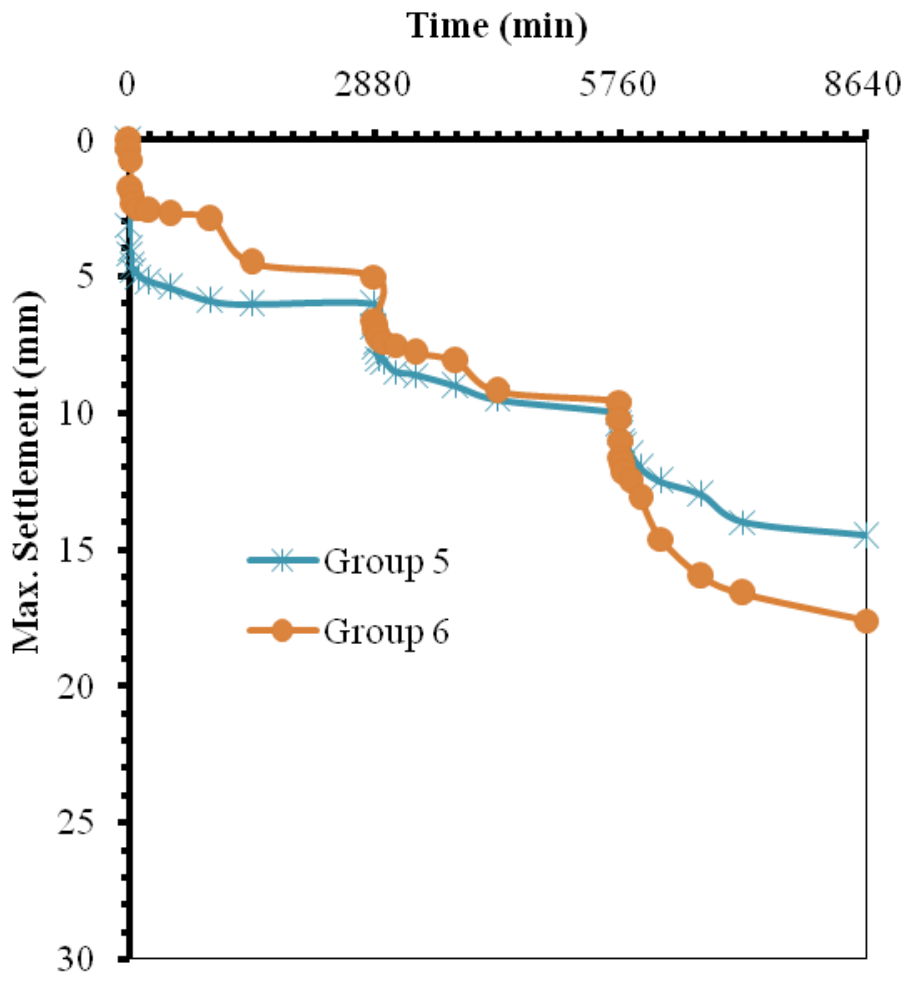

Fig, 6 Time-Settlement curve for the cases of dynamic loads with $\omega=450 \mathrm{rpm}$ 


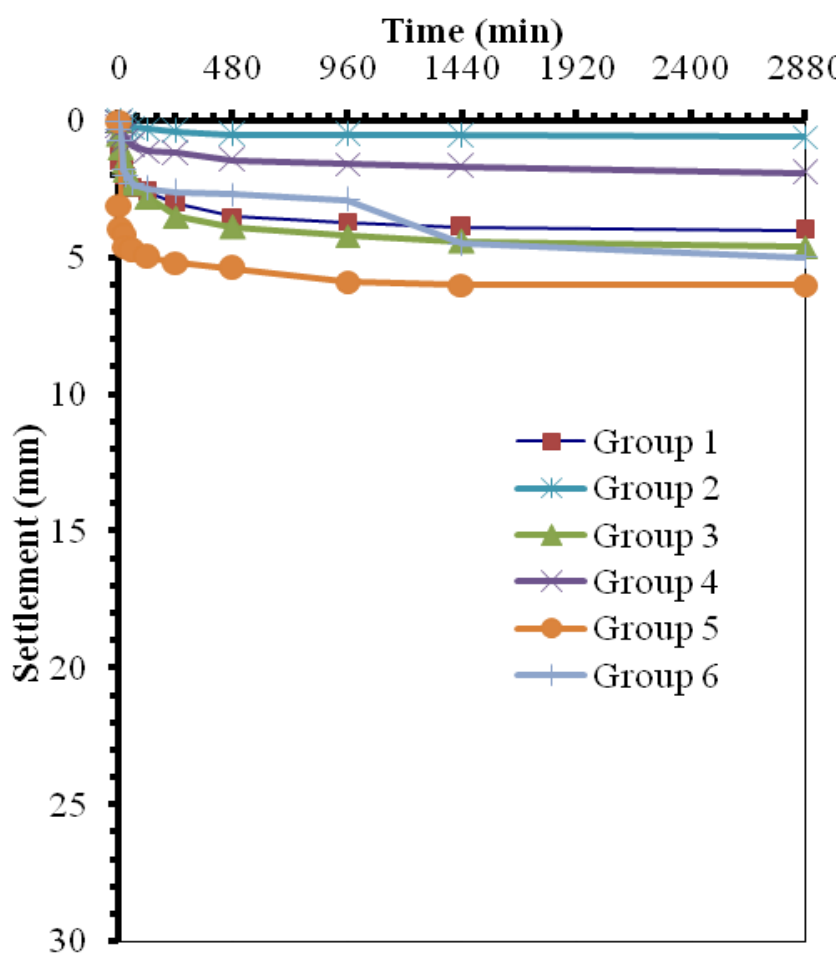

Fig. 7 Time -settlement curve of all groups under stress $20 \mathrm{kN} / \mathrm{m}^{2}$

Time (min)

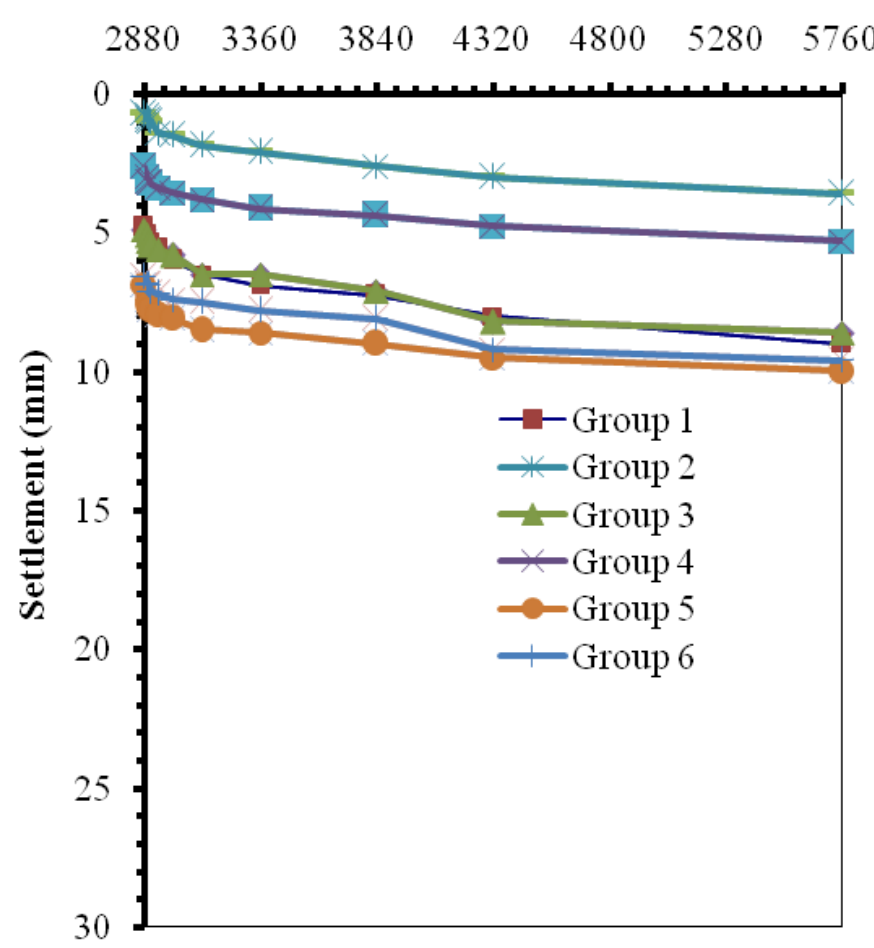

Fig. 8 Time -Settlement Curve ofall groups under stress $40 \mathrm{kN} / \mathrm{m}^{2}$

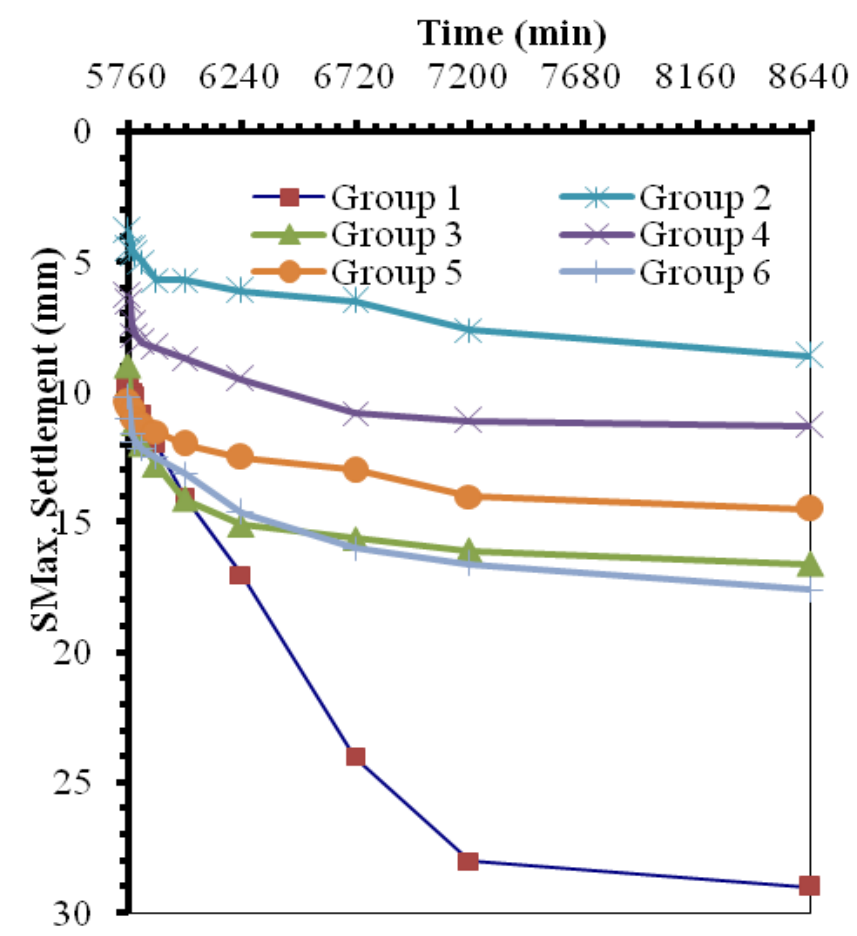

Fig. 9 Time -Settlement Curve of all groups under stress $60 \mathrm{kN} / \mathrm{m}^{2}$

\section{Time (min)}

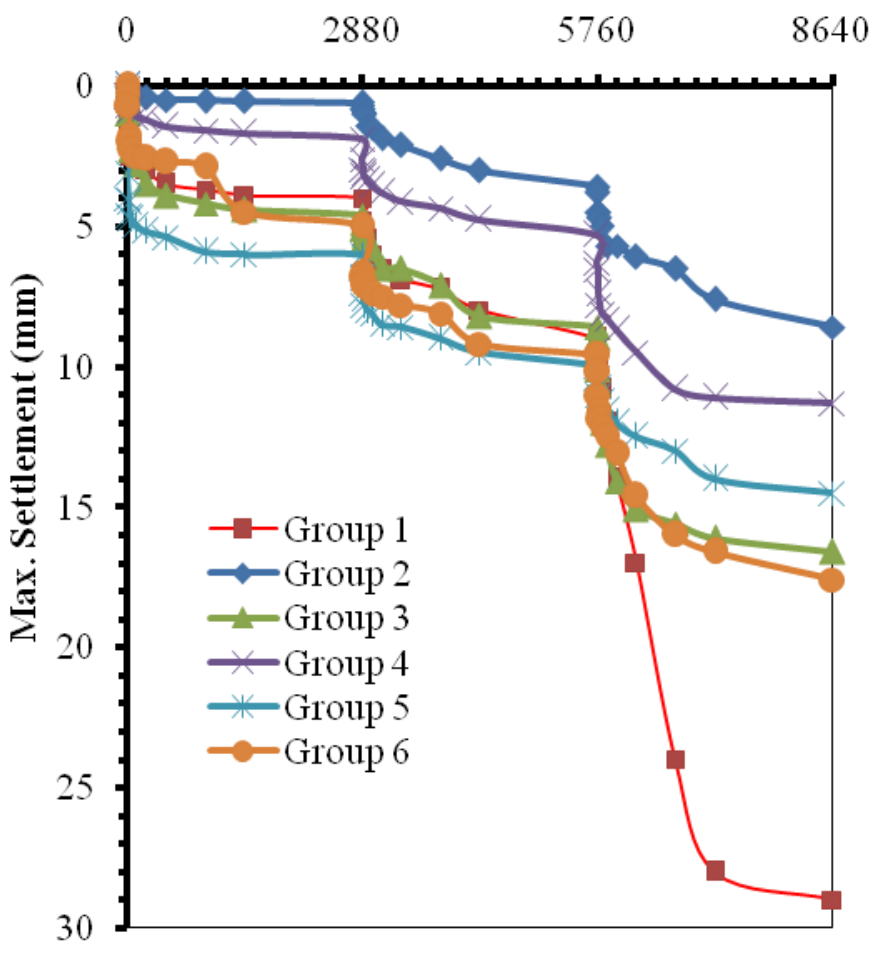

Fig. 10 Time -settlement curve of all groups under all applied stresses 


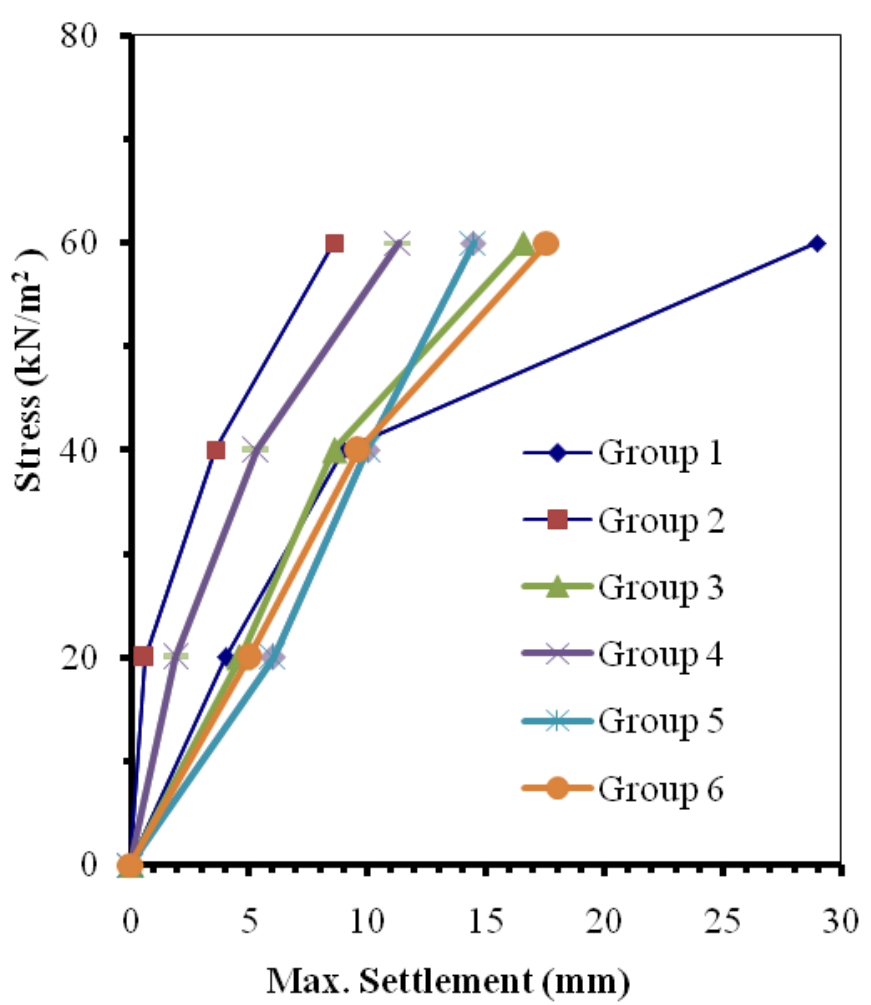

Fig. 11 Applied stress - Max. settlement curve of all groups

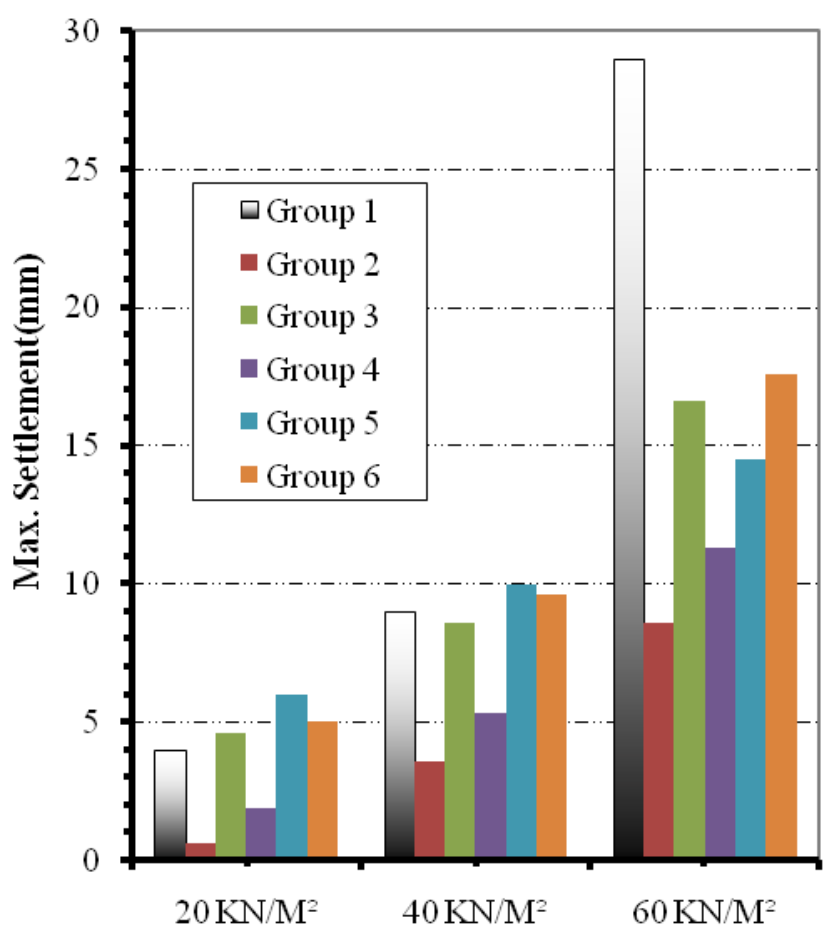

Fig. 12 Max. settlement for all groups under different applied pressure

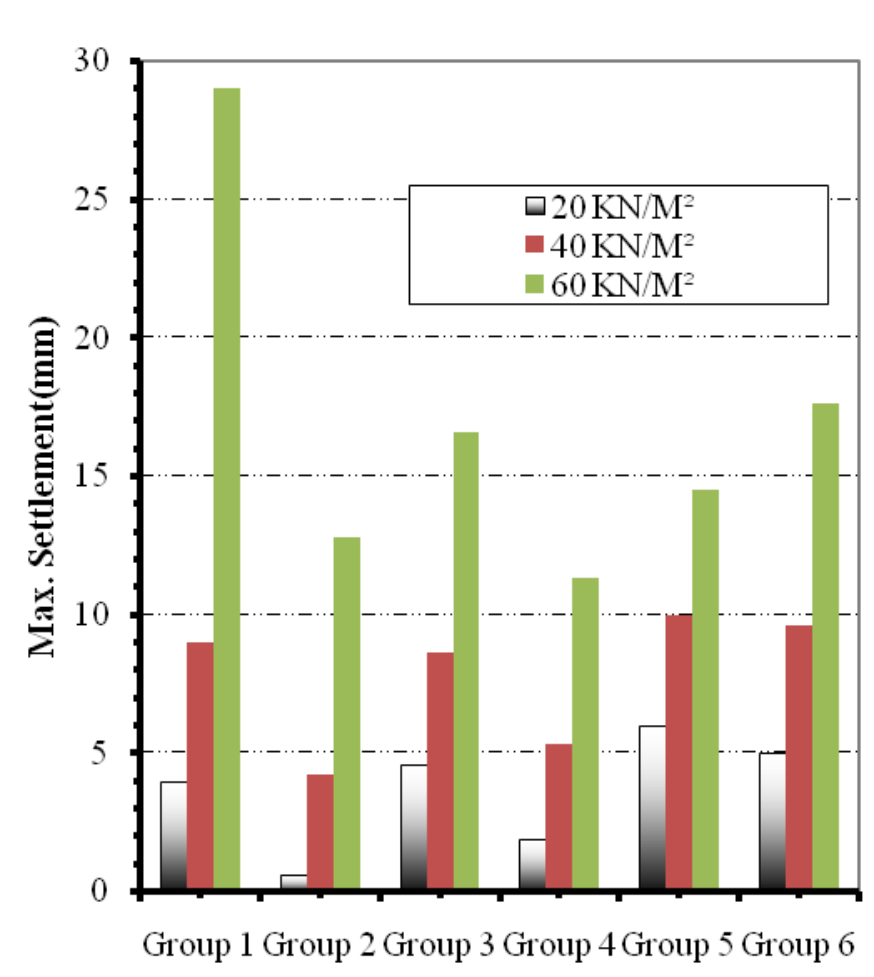

Fig. 13 Max. settlement curve at all stresses

\section{CONCLUSIONS}

This paper presents an experimental study for footing resting on saturated medium soft clay and subjected to both static and dynamic loading. The aim of the study is to highlight the effect of utilizing Expanded Polystyrene Geofoam as settlement reducer. The experimental work was divided into six groups with total eighteen different case studies depending on the applied stress at each group.

Based on the results of this study, the following may be concluded:

1- Static loads cases gave the highest settlement reductions when using EPS. In this case, about $70 \%$ reductions in the total settlements were recorded.

2- The circular operating frequency of the dynamic loads affects the settlement value, whereas the lower value of circular operating frequency gave higher settlement especially at earlier loading stages.

3- Under dynamic loading, the utilization of EPS as a replacement layer for medium soft clay would be considerably beneficial, especially at higher circular operating frequency. The resulting reductions in the total settlement will allow for higher design stresses. 


\section{REFERENCES}

[1] S. Prakash andV. K. Puri, "Foundation for Vibrating Machines "Special Issue, April-May 2006, of the Journal of Structural Engineering, SERC, Madras. INDIA,2006

[2] M. Y. Fattah,M.Hamood and I. A. A. Al-Naqdi, "Finite element analysis of a piled machine foundation", Article in Structures \& Buildings, April 2015.

[3] M. M. Hassan, N. Cheraghi, G. W Norlander and J. Baggal, "Dynamic Analysis of Machine Foundation Systems" CSCE 2013 General Conference - Montréal, 2013.

[4] Ion Vlad, "Machine Foundations and Blast Engineering Vibrations Case Study" InternationalConferences on Recent Advances in Geotechnical Earthquake Engineering and Soil Dynamics, 2007.

[5] A.M.A.Alzawi, "Vibration Isolation Using In-filled Geofoam Trench Barriers" (2011). Electronic Thesis and Dissertation Repository. Paper 265, http://ir.lib.uwo.ca/etd

[6] A.F.Elragi,"Selected Engineering Properties and Applications of EPS Geofoam", Softoria,2006.

[7] G.E. Abdelrahman and A.F. Elragi, "Behaviour Improvement of Footing on Soft Clay Utilizing Geofoam", The 10th Arab Structural Engineering Conference, Kuwait, 2006.

[8] Stefan Florjanic and Arno Frei, "Dynamic Loading on Pumps", Proceedings of the tenth international pump users, 1995. 